\title{
AS COMPETÊNCIAS APRIMORADAS DOS PARTICIPANTES DE UMA GAMIFICAÇÃO ONLINE PROMOVIDA PELO PET CIVIL UFPA
}

DOI: 10.37702/2175-957X.COBENGE.2021.3662

Lucas Luciano Sousa Batista - Isbatista.lucas40@gmail.com

Universidade Federal do Pará UFPA

Travessa Lomas Valentinas 460

66080-321 - Belém - PA

Henrique Silva Moraes Filho - h.filhohf7@gmail.com

Universidade Federal do Pará

Passagem Dezenove de Março 159

67010-730 - Ananindeua - PA

Olga Maria Pinheiro Pinheiro - olgapinheiro99@gmail.com

Universidade Federal do Pará

Travessa Timbó 1293

66083-049 - Belém - PA

Nívea G B Albuquerque - nivea@ufpa.br

UFPA

C) IMPERIO AMAZONICO 15

66613-080 - BELEM - PA

Resumo: A pandemia do covid-19 criou um ambiente de dificuldades, principalmente na área da educação, com escolas e universidades fechadas, funcionando de forma virtual, os estudantes precisaram se adaptar. Assim, buscar ferramentas novas e capazes de facilitar o aprendizado, se torna algo ainda mais necessário. Um exemplo de atividade já conhecida no âmbito profissional, mas pouco utilizada na educação superior: a gamificação. Este estudo descritivo-quantitativo busca identificar as competências adquiridas por alunos de engenharia civil ao participar de uma gamificação. Através de uma análise dos dados de participação coletados em um jogo realizado pelo grupo PET (Programa de Educação Tutorial) de engenharia civil da UFPA, este trabalho conclui que existe uma forte capacidade de uma gamificação auxiliar o desenvolvimento do ensino de habilidade menos técnicas, mas de igual importância para o mercado de trabalho, como a tomada de decisão, leitura de comportamento de terceiros e 
oratória.

Palavras-chave: Gamificação. Mercado de trabalho. Desenvolvimento sustentável. 


\section{AS COMPETÊNCIAS APRIMORADAS DOS PARTICIPANTES DE UMA GAMIFICAÇÃO ONLINE PROMOVIDA PELO PET CIVIL UFPA}

\section{INTRODUÇÃO}

O termo gamification (ou em português, gamificação) foi criado em 2002 pelo programador e inventor Nick Pelling, nascido no Reino Unido, o grande objetivo dessa ideia de Nick era trazer os mecanismos utilizados nos jogos para o contexto da vida real, procurando sempre resolver e solucionar problemas. A princípio entender que jogos ou videogames podem ser soluções para um maior rendimento dos funcionários de empresas, de alunos de escolas e universidades é bastante complicado e difícil, no entanto as experiências realizadas nos últimos anos indicam que, sim a gamificação é um meio promissor para o crescimento profissional, acadêmico e social para toda a sociedade (AZEITEIRO et al., 2015), alguns exemplos são: Startups como a Bliive; aplicativos para corrida, como o pioneiro $\mathrm{N}+$, da Nike, temos os "jogos das empresas" onde os funcionários recebem prêmios reais ou virtuais por conseguir algum cliente ou vender algum produto, entre outros exemplos.

Desta forma, o game realizado pelo Grupo PET Civil UFPA no ano de 2020 denominado "comPETição", com a proposta de que diante do momento vivenciado decorrente da pandemia do coronavírus (COVID - 19), fosse possível proporcionar um "treinamento" para os futuros engenheiros, trazendo menos estresse e maior diversão nesse processo, na "comPETição" os participantes foram incentivados a solucionar situações problemas relacionadas à engenharia civil, após a realização do game foi constatado o sucesso no âmbito acadêmico universitário e até profissional.

\section{METODOLOGIA}

O presente trabalho faz uma análise das competências adquiridas pela participação no jogo comPETição e do processo de realização do mesmo, essa análise foi realizada a partir de um estudo da arte das etapas e procedimentos realizados na elaboração da gamificação, além disso foram analisados os resultados obtidos na plataforma em que o jogo foi realizado, que nesse caso foi uma rede social.

\subsection{Estrutura da gamificação}

Em primeira análise vale ressaltar que, o game foi estruturado e organizado por meio de um edital, no qual estavam presentes as regras, deveres e disposições necessárias para que todos os participantes compreendessem da melhor maneira possível a gamificação e proporcionou maior segurança e credibilidade para a realização dele.

A plataforma utilizada para a realização do game foi uma rede social de grande acesso, em uma conta do grupo PET Civil UFPA, na qual foi trabalhado bastante a interação com os usuários que são majoritariamente alunos do curso de engenharia civil. Com isso, a função da plataforma utilizada foi a de teste, na qual foi escolhido o modo de votação, por conseguinte seriam criadas caixas de votação, as quais poderiam ser respondidas durante 24h.

Importante frisar que esse game foi realizado de maneira totalmente gratuita, foram criados 19 avatares (criação pelos próprios integrantes do PET e tutora) para serem 
escolhidos pelos participantes, cada um dos avatares possuía: um nome, características e um CHA (acrônimo para conhecimento, habilidade e atitudes, sendo considerado como o tripé das competências, que se manifesta na forma de pensar, sentir e agir do indivíduo. Foram formados seis grupos contendo de 3 a 4 avatares sorteados para competir em cada partida, sendo cada partida em um dia de semana e um total de 5 partidas por semana, formando uma rodada, ou seja, foi uma rodada por semana. O total de rodadas no jogo foram três.

Ademais, cada grupo teve uma situação problema específica, na qual os participantes precisaram escolher o avatar mais adequado para aquela situação. Os avatares possuíam diferentes níveis em diversas hard skills e soft skills (FAN; WEI; ZHANG, 2017), e com isso dependendo da situação um deles seria o mais adequado. Também houve um bônus, em que cada participante poderia justificar o seu voto, de forma opcional, por meio de um vídeo publicado também na rede social do grupo PET Civil UFPA, e assim, o participante receberia uma pontuação extra.

Antes de explicitar e descrever como foi a jogabilidade, é necessária uma explicação acerca das definições das palavras utilizadas no game e informações importantes sobre ele. Então, temos que, Avatares: foram os personagens fictícios criados pelo grupo PET, os quais tinham um CHA inicial igualitário para todos, no entanto distribuído de maneira diferente para cada avatar. Situação Problema: um desafio, uma fase, um contexto criado pelos integrantes do grupo PET, envolvendo um problema especifico de engenharia civil, no qual os participantes tiveram a oportunidade de votar no avatar mais adequado para resolver a situação. Rodadas: um ciclo completo de 5 partidas ou 1 semana. Partidas (Grupos): foram as divisões internas (subdivisões) das rodadas, cada uma delas irá possuir 3 ou 4 avatares competindo entre si, em uma situação problema. Dessa forma, é possível compreender como funcionam os mecanismos utilizados para a realização da gamificação.

Houve mecanismos auxiliares utilizados para a elaboração do game, por exemplo as pontuações foram contabilizadas em uma planilha (Figura 1), a qual foi sistematizada para que houvesse a soma das pontuações, já as informações e características dos avatares foram confeccionadas em uma plataforma de design digital (Figura 2).

Para que fosse possível a organização das rodadas e realizasse a definição de quais seriam os avatares e situações problemas de cada partida referente a cada rodada, para haver melhor compreensão dessa situação foi realizado um sorteio para a divisão das situações problemas e os avatares foram organizados de modo que não houvesse repetição de avatares na rodada. Com isso, temos o fechamento dos mecanismos utilizados para a realização da gamificação.

Figura 1 - Exemplo da tabela de contabilização de pontos dos participantes

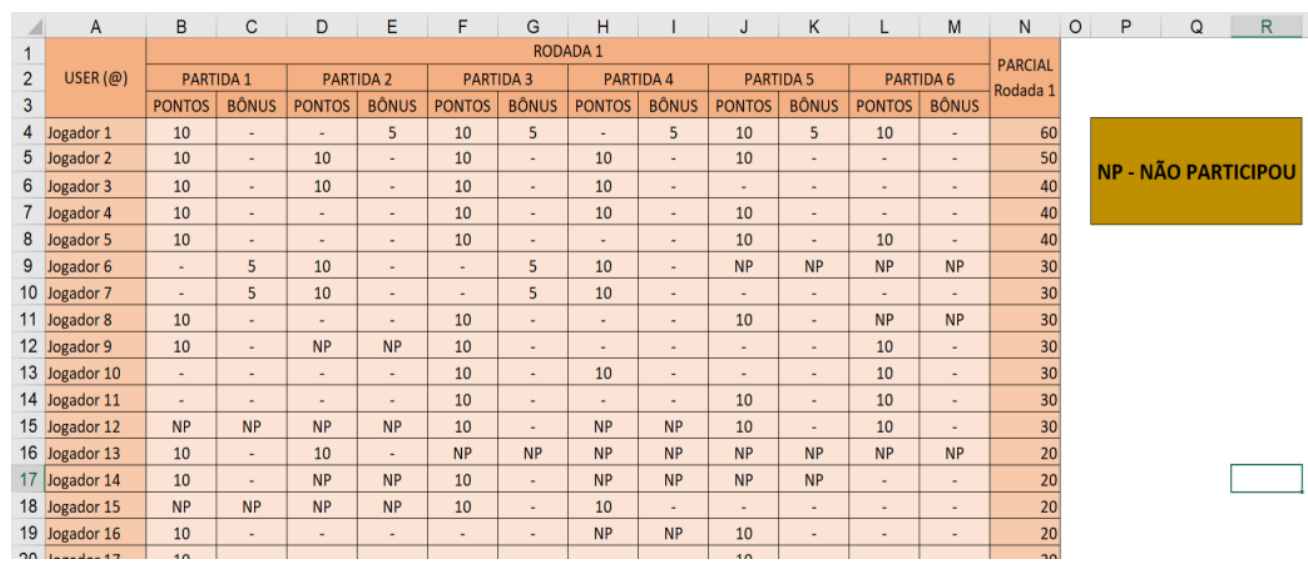

Fonte: Autores 


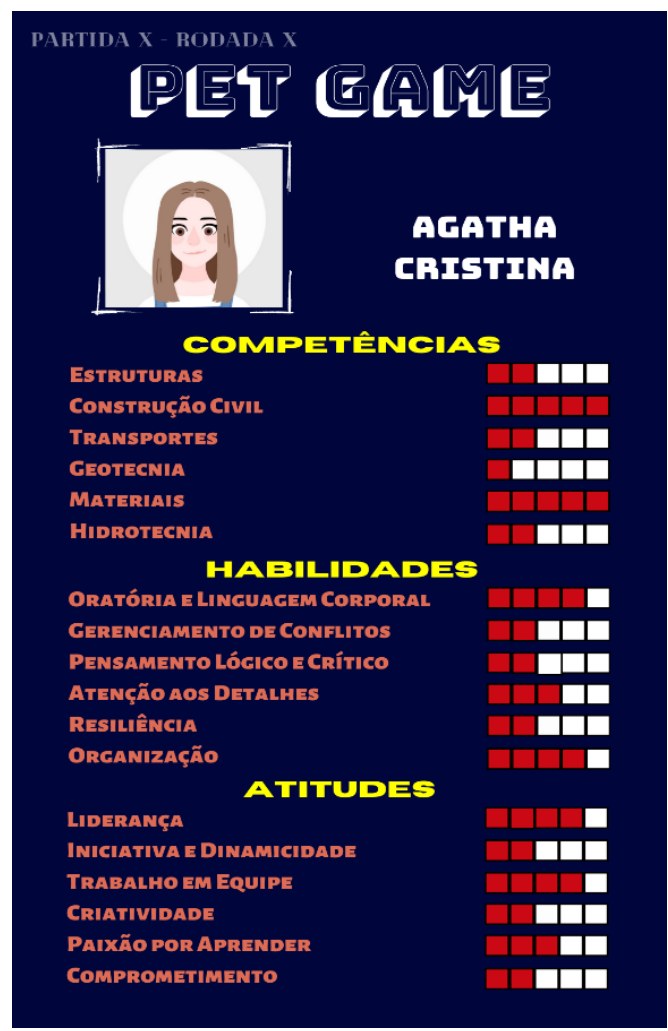

Fonte: Autores

\subsection{Organização do Jogo e suas Pontuações}

Neste tópico serão tratadas questões a respeito da organização e pontuação da gamificação. Em um primeiro momento, vale destacar que a gamificação foi organizada da seguinte maneira: foram 3 rodadas, onde cada uma ocorrerá em 1 semana, e nessas rodadas eram 6 grupos contendo cada um 3 ou 4 avatares para disputarem entre si, a fim de serem escolhidos como os mais indicados para cada situação problema, no caso serão 6 situações problemas por rodada. Antes de começar a realização de cada etapa da gamificação foi elaborado um cronograma a ser seguido a fim de se obter maior gestão de tempo. A partir disso, eram organizadas as postagens que seriam colocadas para o público na rede social, desde a chamada de atenção para o início de cada partida até o resultado final da partida com a porcentagem de votos para cada avatar.

Acerca do funcionamento da pontuação da gamificação, temos que 0 avatar vencedor de cada rodada era aquele que obtivesse a maior quantidade votos dos participantes, e todos os participantes que votaram neste avatar vitorioso, ganhariam uma pontuação pré-determinada. Essa pontuação dos participantes era acumulativa ao longo de todas as partidas, além de serem acrescidas da pontuação extra dos vídeos opcionais de justificativa que os participantes mandaram. Ao final de 15 partidas (3 rodadas), o participante com maior quantidade de pontos seria considerado o vencedor da gamificação.

Uma estratégia adotada pela organização foi a de aumentar a pontuação ganha com votação e com o envio do video a cada rodada, o principal objetivo dessa estratégia era providenciar uma competitividade maior com eventuais participantes que entrassem na competição quando ela já estivesse ocorrendo, aumentando assim as chances de mais participantes aderirem a gamificação mesmo que entrem após o início. 
Dessa forma, verificamos e compreendemos como funcionou a organização e o sistema de pontuações da gamificação.

\subsection{Método de análise}

Das análises feitas acerca da gamificação, temos que a metodologia realizada para cada uma foi a seguinte:

Primeiramente se tratando da análise dos participantes foram verificados os dados de participação e frequência dos jogadores em cada rodada e por meio da elaboração de gráficos e tabelas foi possível obter as conclusões e os resultados necessários.

Por conseguinte, vale ressaltar que para a realização da segunda análise que foi referente às competências adquiridas, foram escolhidas habilidades que estão totalmente conectadas e ligadas ao que a gamificação pode proporcionar, e foi por meio da participação e feedback dos participantes em cada atividade em conjunto com o referencial bibliográfico pesquisado que foi possível a realização da análise e obter os resultados.

\section{RESULTADOS}

\subsection{Participação}

Neste tópico iremos discutir sobre a interação dos participantes com a gamificação realizada, iremos abordar assuntos como a participação e a evolução dos participantes ao longo da gamificação e desta forma entender qual o papel da gamificação nesses participantes.

Primeiramente vamos analisar a participação direta nas respostas da gamificação, a figura 3 ( $a, b$ e c), mostra um ganho de participação alto entre a $1^{\circ}$ e $2^{\circ}$ semana, porém houve uma queda nas participações na $3^{\circ}$ semana. $O$ aumento inicial representa um ganho orgânico de participantes, ou seja, os participantes foram aumentando devido a um ganho de popularidade natural da gamificação.

Enquanto isso a diminuição dos participantes no outro momento, provavelmente ocorre, pois, a $3^{\circ}$ semana é também a última, e isso significa que apenas alguns poucos jogadores tinham a possibilidade de ganhar, isso provavelmente desencorajou os demais a continuar participando, devido a isso fica claro que nossa ferramenta de aumento da pontuação gradual surtiu efeito entre a primeira e segunda semana, porém não funcionou para a última semana.

Outra análise importante, é a constância de cada jogador ao participar das partidas da gamificação. Neste trabalho foi analisada a quantidade de partidas que cada jogador participou durante as rodadas, dessa forma é possível visualizar a constância de participação em um contexto geral (Tabela 1).

Durante todas as rodadas a grande maioria dos participantes jogaram uma única vez por rodada, indicando que não houve uma adesão por parte de todos os participantes. Porém também podemos visualizar que houve um interesse constante ao longo de toda a gamificação, por parte dos participantes, em experimentar o jogo. Isso pode significar um aumento de participação em outras edições conforme o jogo for se tornando mais conhecido, indicando também, que a gamificação nas redes sociais cumpre um papel de ser atrativa. 
Figura 3 - A: participações por rodadas na $1^{\circ}$ semana; B: participações por rodadas na $2^{\circ}$ semana; C: participações por rodadas na $3^{\circ}$ semana.
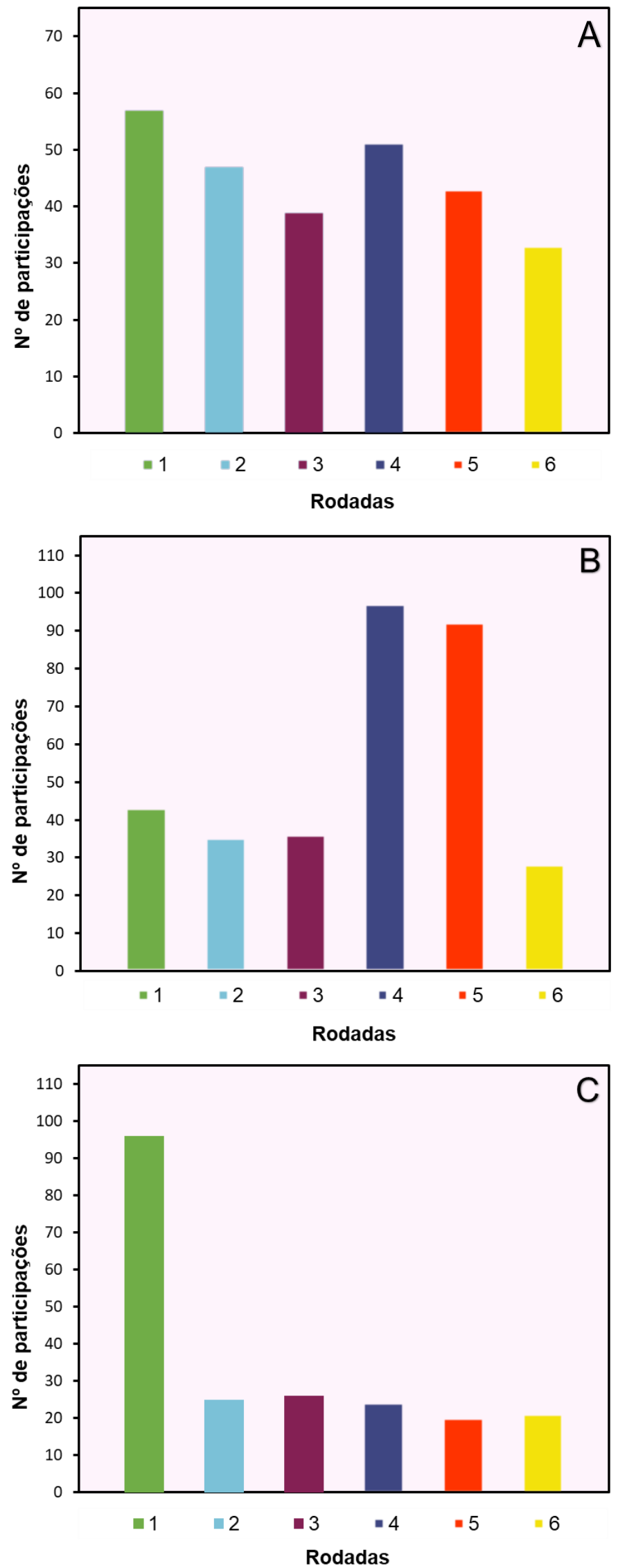

Fonte: Autores 
28 a 30 de SETEMBRO

Tabela 1 - Quantidade de participantes por quantidade de participações durante a semana.

\begin{tabular}{c|c|c|c|c|c|c|c}
\hline \multicolumn{7}{c}{ Quantidade de participantes por quantidade de participações } \\
\hline \multirow{2}{*}{ Quantidade de participações } & $\mathbf{6}$ & $\mathbf{5}$ & $\mathbf{4}$ & $\mathbf{3}$ & $\mathbf{2}$ & $\mathbf{1}$ \\
\hline \multirow{2}{*}{$\mathbf{1}^{\circ}$ Semana } & Quantidade & 13 & 8 & 5 & 11 & 0 & 55 \\
\cline { 2 - 8 } & $\%$ & $14 \%$ & $9 \%$ & $5 \%$ & $12 \%$ & $0 \%$ & $60 \%$ \\
\hline \multirow{2}{*}{$2^{\circ}$ Semana } & Quantidade & 15 & 6 & 5 & 4 & 28 & 123 \\
\cline { 2 - 8 } & $\%$ & $8 \%$ & $3 \%$ & $3 \%$ & $2 \%$ & $15 \%$ & $68 \%$ \\
\hline \multirow{2}{*}{$2^{\circ}$ Semana } & Quantidade & 14 & 2 & 1 & 1 & 11 & 89 \\
\cline { 2 - 8 } & $\%$ & $12 \%$ & $2 \%$ & $1 \%$ & $1 \%$ & $9 \%$ & $75 \%$ \\
\hline
\end{tabular}

Fonte: Autores

\subsection{Análise das competências adquiridas}

\section{Tomada de decisão}

A gamificação realizada cobrou dos seus competidores uma tomada de decisão ao pedir para votarem em algum dos avatares, pois baseado nas competências dele e na problemática apresentada, eles deviam escolher o avatar que melhor se adequa. Essa escolha requer dos participantes um pensamento crítico, pois eles deviam relacionar e escolher as competências que mais seriam requeridas para a resolução de cada problema, aumentando seu pensamento crítico sobre a atuação prática das competências de um indivíduo no mercado de trabalho. A tomada de decisão é uma competência muito estudada no ambiente empresarial e administrativo, Hall-Ellis (2015) divide a tomada de decisão em 3 partes:

- $\quad$ Formação do problema e formação do objetivo

- $\quad$ Identificação e geração das alternativas

- $\quad$ Análise e escolha da melhor alternativa

Por limitações da dinâmica através de uma rede social, como foi a gamificação "competição", as duas primeiras partes da tomada de decisão foram pré-definidas pela organização do jogo, desta forma, os participantes puderam trabalhar somente a última parte. Contudo, é importante ressaltar a importância da análise e escolha da alternativa para a engenharia, pois é onde culmina a habilidade da tomada de decisão no dia a dia de um engenheiro.

\section{Leitura das decisões de terceiros}

A estrutura do jogo foi montada de forma que o avatar mais votado seria o ganhador e junto com ele, todos que votaram nele ganhariam a pontuação. Desta forma, além de analisar as competências individualmente, era necessário analisar o comportamento da maioria pois para ganhar, era necessário estar no grupo maior. desta forma, os participantes treinaram uma competência muito importante para a vida profissional, a habilidade de prever o comportamento dos concorrentes ou do público.

\section{Oratória e defesa de ideias}

Um dos aspectos presentes na gamificação, foi a pontuação extra mediante vídeos de justificativa de votos. Basicamente, de forma opcional, todos os participantes poderiam enviar um vídeo curto de si próprio explicando e defendendo seu voto, mostrando seus critérios. Dessa forma, foi treinada a oratória dos participantes, bem como a formação de 
uma estrutura de defesa de ideias. A oratória corresponde à habilidade de se comunicar e convencer uma audiência específica através das palavras (BAIRD, 2009), dessa forma, se torna uma habilidade imprescindível para o mercado de trabalho em qualquer área que envolva o debate ou necessite de capital humano.

\section{CONCLUSÕES}

A pandemia do covid-19 criou um ambiente de dificuldades, provocando uma grande modificação na vida das pessoas, inclusive na área da educação, com escolas e universidades fechadas, funcionando de forma virtual, os estudantes precisaram se adaptar de uma forma brusca, trazendo desconforto e consequentemente dificuldades. Uma gamificação online, traz uma nova possibilidade no campo do ensino, inclusive de engenharia como foi demonstrado nesse trabalho. As competências desenvolvidas se mostram importante no mercado de trabalho (NOGUEIRA; FRANCISCO; LEMOS, 2019) e transformam o ensino de engenharia em algo além das matérias técnicas, ampliando as capacidades comportamentais e de capital humano dos participantes.

\section{Agradecimentos}

Agradecemos ao Ministério da Educação (MEC) e a Pró-reitoria de Ensino da UFPA (PROEG) por possibilitarem a existência e manter o funcionamento do nosso Programa de Educação Tutorial (PET), bem como o apoio através de bolsas aos discentes. Agradecemos também a todos os integrantes do grupo, que apesar de não participarem da produção deste trabalho, participaram da organização da gamificação.

\section{REFERÊNCIAS}

AZEITEIRO, U. M. et al. Education for sustainable development through e-learning in higher education: Experiences from Portugal. Journal of Cleaner Production, v. 106, p. 308-319, 2015.

BAIRD, A. C. Oratory, 2009. (Nota técnica).

FAN, C. S.; WEI, X.; ZHANG, J. Soft Skills, Hard Skills, and the Black/White Wage Gap. Economic Inquiry, v. 55, n. 2, p. 1032-1053, 2017.

HALL-ELLIS, S. D. Nudges and decision making: a winning combination. Bottom Line, v. 28, n. 4, p. 133-136, 2015.

NOGUEIRA, A. A.; FRANCISCO, F. E.; LEMOS, W. O Impacto Das Soft Skills Sobre a Liderança. p. 1-9, 2019.

\section{THE ENHANCED SKILLS OF PARTICIPANTS IN AN ONLINE GAMIFICATION PROMOTED BY PET CIVIL UFPA}

Abstract: The covid-19 pandemic created an environment of difficulties, especially in the area of education, with schools and universities closed, functioning in a virtual way, students had to adapt. Thus, looking for new tools capable of facilitating learning becomes something 
even more necessary. An example of an activity already known in the professional field, but little used in higher education: gamification. This descriptive-quantitative study seeks to identify the skills acquired by students of civil engineering when participating in a gamification. Through an analysis of the participation data collected in a game carried out by the PET (Tutorial Education Program) group of civil engineering at UFPA, this work concludes that there is a strong capacity for gamification to assist the development of less technical skills, but of equal importance to the market work, such as decision-making, reading of third-party behavior and public speaking.

Keywords: Gamification; Labor market; Sustainable development 